\title{
Um estudo sobre o brincar de crianças autistas na perspectiva histórico-cultural
}

\author{
Alessandra Dilair Formagio Martins \\ Maria Cecília Rafael de Góes
}

\begin{abstract}
Resumo
O brincar de crianças autistas é descrito como muito restrito e peculiar. Com a preocupação pela busca de práticas educativas promissoras, a presente pesquisa tomou como referência a teoria histórico-cultural e teve o objetivo de analisar os modos como crianças autistas se orientam para o outro e para o objeto durante a atividade lúdica. O estudo focalizou três sujeitos, com idade de seis a doze anos, durante sessões de brincadeira coordenadas pela primeira autora, que interagia com as crianças atribuindo significado às suas ações e ao uso de brinquedos, e encorajava a emergência de jogos imaginativos. Os dados foram organizados sob dois temas: modos de brincar das crianças e modos de atuação do adulto. Os achados indicam que a mediação da pesquisadora propiciou a ocorrência de muitos momentos de orientação para o outro e de uso contextualizado de objetos, incluindo ações do jogo de papéis.
\end{abstract}

Palavras-chave: crianças autistas, brincadeiras, desenvolvimento do brincar.

\section{A study about play behavior of autistic children from the historical-cultural perspective}

\begin{abstract}
Play behavior of autistic children is described as very restricted and peculiar. Concerned with the search for promising educational practices, we use historical-cultural theory to analyze the ways through which autistic children orient themselves towards others and objects in situations of play. The study focuses on three subjects, aged between six and twelve years, during play sessions. These sessions were coordinated by the first author, who ascribed meaning to the children's actions and use of toys, and encouraged the emergence of imaginative play. Data were organized under two topics: children's modes of playing and adult's modes of participation. The findings suggest that the researcher's mediation allowed for the occurrence of many instances of orientation towards the other as well as moments of contextualized use of objects, including actions of role play.

Keywords: autistic children, tricks, childhood play development.
\end{abstract}

\section{Un estudio sobre la actividad de jugar de niños autistas en perspectiva histórico-cultural}

\section{Resumen}

La actividad de jugar de niños autistas se describe como muy restricta y peculiar. A partir de la preocupación con la busca de prácticas educativas promisoras la presente investigación tomó como referencia la teoría histórico-cultural y tuvo el objetivo de analizar los modos como niños autistas se orientan para el otro y para el objeto durante la actividad lúdica. El estudio se realizó con tres sujetos con edades entre seis a doce años, durante sesiones de juego coordinadas por la primera autora que interactuaba con los niños atribuyendo significado a sus acciones y al uso de juguetes, incentivando juegos imaginativos. Se organizaron los datos en dos temas: modos de jugar de los niños y modos de actuar del adulto. Los resultados indican que la mediación de la investigadora permitió acontecer muchos momentos de orientación para el otro y el uso contextualizado de objetos, incluyendo acciones del juego de roles.

Palabras Clave: niños autistas, jugar, desarrollo del juego. 


\section{Introdução}

O autismo é classificado como um distúrbio global do desenvolvimento, no qual há um comprometimento em diversas áreas do comportamento e do psiquismo. Na descrição da Classificação Internacional de Doenças - CID 10 (Organização Mundial da Saúde, 1993), essa patologia é definida como um transtorno invasivo do desenvolvimento, identificado pelo surgimento antes da idade de 3 anos e "pelo tipo característico de funcionamento anormal em todas as três áreas de interação social, comunicação e comportamento restrito e repetitivo" (p. 247). Também na discussão atual dos diferentes quadros abrangidos pelos Transtornos do Espectro do Autismo (TEA) é salientada a sintomatologia básica da tríade autística, referente a problemas na interação social, comunicação e padrão comportamental (Schwartzman \& Araújo, 2011).

Em relação ao brincar, foco do presente trabalho, a descrição da CID 10 indica que essa atividade encontra-se alterada pelas características gerais do transtorno:

A condição é também caracterizada por padrões de comportamento, interesses e atividades restritos, repetitivos e estereotipados. Isto toma a forma de uma tendência a impor rigidez e rotina a uma ampla série de aspectos do funcionamento diário; usualmente, isto se aplica tanto a atividades novas como a hábitos familiares e a padrões de brincadeiras. (Organização Mundial da Saúde, 1993, p. 248)

Na mesma linha, o DSM-IV (American Psychiatric Association, 1995) indica que, nos casos de autismo, em geral as brincadeiras imaginativas estão ausentes ou apresentam prejuízo acentuado. Além disso, as crianças tendem a não se envolver nos jogos de imitação e rotinas simples da infância, ou o fazem fora de contexto e de um modo mecânico.

Estudos com sujeitos autistas tendem a reiterar a indicação de que eles não conseguem brincar com seus pares e fazer amigos, carecem de criatividade e iniciativa, apresentam habilidades sociais muito limitadas e, particularmente, fracassam no desenvolvimento da empatia. Nessa linha, costuma-se afirmar que as crianças autistas demonstram uma preferência por objetos e não por pessoas. Como descreve Soifer (1992), "suas brincadeiras são solitárias e consistem geralmente em fazer rodar um carro com as mãos (meninos) ou ter nos braços uma boneca (as meninas)" ( $p$. 231). São os objetos que provocam seu interesse e podem ser manipulados por longos períodos. Entretanto, o uso que fazem deles se mostra restrito, seja pela forma repetitiva da manipulação, seja pela preferência de objetos com determinadas características (Marcelli,1998).

Tendo em vista as dificuldades de comunicação e interação dessa criança, as relações que os outros estabelecem com ela podem mostrar-se comprometidas muitas vezes desde o nascimento, ou assim que se evidencia o transtorno. Não se trata de culpabilizar pais e familiares, mas de considerar que os fracassos na interação se devem em boa parte ao modo como as pessoas próximas reagem à falta de respostas e de contato do autista, o que certamente afeta seu desenvolvimento, muitas vezes cristalizando o quadro já instalado.

Bosa (2002) discute a dificuldade que os outros têm para compreender a forma como os autistas comunicam suas necessidades e desejos, e argumenta que um olhar mais atento permite observar o grande esforço que esses sujeitos despendem para encontrar recursos que propiciem a compreensão do que estão expressando. Numa análise minuciosa de registros de filmagem, a autora verificou que o olhar que dirigem para as pessoas, muitas vezes descrito como quase ausente, é na verdade mais frequente do que se imagina, particularmente nas situações em que a criança necessita do adulto. Entretanto, são olhares breves e quase imperceptíveis. Essa característica e a baixa frequência podem ser interpretadas pelo adulto como uma incapacidade de entender "a função comunicativa do olhar" para compartilhar experiências com as pessoas. Bosa (2002) enfatiza "que essa suposição parece trivial, mas faz uma diferença quando aplicada em um contexto de intervenção com os pais: não olhar porque não compreende a extensão das propriedades comunicativas do afeto e do olhar é diferente de não querer olhar" (p. 36, grifo da autora).

Algo semelhante ocorre na esfera da brincadeira, como mostra o estudo de Bagarollo (2005), referenciado na abordagem histórico-cultural. Assim como as ações da criança são percebidas como movimento e manipulação sem sentido, a mãe e as pessoas próximas vão deixando de significá-las. Como resultado, persiste um brincar limitado e empobrecido, já que possíveis transformações não são incentivadas. Então, salienta a autora, instala-se um círculo vicioso em que o diagnóstico leva à atuação guiada pela crença nos limites circunscritos pelo diagnóstico, o que, por sua vez, faz estagnar o nível de funcionamento psíquico, ao invés de elevá-lo, "confirmando" as características previstas.

$\mathrm{Na}$ criança normal, o processo do brincar ocorre de forma natural, em que adultos e parceiros interagem com ela, que logo aprende a agir com objetos de forma lúdica e a compartilhar a atividade. Já nas crianças autistas esse processo não é tão simples, pode ser longo e trazer grandes frustrações a pais, familiares e educadores, que acabam desacreditando da viabilidade e importância dessa área tão propícia ao desenvolvimento.

Além do baixo investimento da família nas possibilidades do brincar, o espaço destinado a essa atividade nas instituições voltadas a esse público é bastante limitado, quando não totalmente ausente (Martins, 2010). Em geral, no âmbito da clínica e principalmente no contexto educacional, os profissionais ainda põem o foco no treinamento, questão essa que tem sido objeto de alguns estudos fundamentados na teoria histórico-cultural. As proposições dessa teoria são exploradas na busca de alternativas de trabalho educacional que favoreçam a interação social e a elaboração de significados, o que não pode ser alcançado por uma visão que enfatiza o treino de habilidades, utiliza formas de comunicação pouco vinculadas à significação e tenta estabelecer o controle da atenção por meio de ativi- 
dades individualizadas e com marcante redução do campo de estímulos (Bragin, 2011; Orrú, 2008, 2010). Há também estudos que abordam obstáculos e possibilidades no âmbito das propostas de inclusão de alunos com autismo, na etapa infantil (Mattos \& Nuemberg, 2011) e na adolescência (Cruz, 2010). As pesquisas sob essa orientação teórica compõem um número ainda pequeno de trabalhos em comparação com os de outras vertentes que dirigem maior atenção aos impedimentos e às formas de atenuar os sintomas ${ }^{1}$.

Essa crítica às práticas educativas e a proposição de uma visão alternativa apontam caminhos promissores e muito relevantes para a atuação e a busca de maior conhecimento do autismo. No intuito de contribuir para a discussão dessa problemática, o presente trabalho explora o referencial da teoria histórico-cultural, particularmente o pensamento de L. S. Vigotski, sobre o papel fundamental do brincar na infância. Concordando com Bagarollo (2005), julgamos que uma extensão das interpretações do autor para o caso do autismo infantil permite apontar para possibilidades de que a brincadeira atue como um aspecto propulsor do processo de desenvolvimento global dessas crianças.

Vigotski e outros teóricos da abordagem histórico-cultural (Elkonin, 1984; Leontiev, 1986) argumentam que o brincar é uma atividade fundamental ao desenvolvimento psíquico da criança e dão ênfase à brincadeira imaginativa ou jogo de papéis. Para aquele autor (Vigotski, 1984), essa forma de jogo surge num momento em que a criança pequena vivencia "tendências não realizáveis", quando ela busca a satisfação de forma imediata, mas se depara com limites da realidade, e no brincar essa satisfação torna-se possível.

Nessa atividade, a criança não só reproduz, mas se emancipa das situações imediato-concretas e age de maneira imaginativa, assimilando suas vivências, ao mesmo tempo em que as retoma de forma criativa. A brincadeira tem base no vivido, mas não se constitui em simples reiteração da realidade conhecida. Nela, a criança usa objetos substitutivos, encena, dramatiza situações e personagens, re-significando essa realidade. Suas ações adquirem uma função representativa e não funcional ou concreta, contribuindo para a elevação dos processos mentais na infância.

A característica central do brincar está no fato de que a criança aprende a agir no campo da significação ao invés de se restringir ao campo perceptual, dependendo mais de suas motivações que das características dos objetos externos. Assim, o campo percebido perde sua força determinante e a criança passa a agir de maneira diversa frente àquilo que vê, operando com significados libertos das características dos objetos e das ações às quais estes estão habitualmente vinculados.

A imaginação, embora tenha um papel fundamental na infância, é uma atividade psíquica complexa necessária em qualquer fase da vida, pois implica um afastamento da

\footnotetext{
1 A respeito dessa ênfase no comprometimento e na patologia, Vasques (2008) realizou uma análise de teses e dissertações da área educacional acerca dos transtornos de desenvolvimento e constatou que a maioria das pesquisas, com diferentes referenciais teóricos, apoiava-se em pressupostos organicistas.
}

realidade, "em uma atividade relativamente autônoma da consciência, que se diferencia da cognição imediata da realidade" (Vigotski, 1999, p. 129). Também o afeto está presente no vínculo entre a função imaginativa e a realidade, pois todo sentimento e emoção manifestam-se nesse processo, ativando impressões, imagens, ideias, baseadas no estado de ânimo do indivíduo. O imaginar é condição para a atividade criadora e amplia o círculo da própria experiência, por participar da assimilação de experiências históricas e sociais alheias (Vigotski, 1987).

Dessa perspectiva, o componente imaginativo da brincadeira infantil tem natureza e origem social, pois a criança reelabora as formas humanas de agir com objetos e de interagir com outros a partir de suas condições concretas de vida, porém criando novas realidades. Ademais, ao brincar, ela se envolve em regras de comportamento e valores sociais, com os quais muitas vezes não conseguiria operar fora dessa atividade.

Nesse sentido, a brincadeira é uma instância fundamental de desenvolvimento na infância, pois, como diz Vigotski (1984):

No brinquedo, a criança sempre se comporta além do comportamento habitual de sua idade, além de seu comportamento diário; no brinquedo é como se ela fosse maior do que é na realidade. Como no foco de uma lente de aumento, o brinquedo contém todas as tendências do desenvolvimento, sob forma condensada, sendo ele mesmo uma grande fonte de desenvolvimento. (p.117)

Como todo processo humano, o desenvolvimento da capacidade lúdica depende das mediações que constituem as vivências na cultura. A mediação social implica a participação do outro no desenvolvimento do sujeito, o que propicia formas de significar o mundo e agir nele. Como afirma Rocha (2005), num estudo sobre o brincar:

As relações entre os sujeitos não se dão de forma direta, mas antes mediada por objetos, instrumentos e pela palavra. Estas formas de mediação são utilizadas não só com objetivos de comunicação, de contato, como com objetivos de regular o comportamento, em sentido duplo, do outro em direção à criança e da criança em relação ao outro. As formas de mediação social, de intervenção de outros sujeitos, com os quais a criança se relaciona desde o início da vida, possibilitam a interação desta mesma criança com os objetos de sua cultura, com as pessoas e, gradativamente, suas operações num plano interpessoal. (p. 33)

A tese da mediação social é particularmente importante para a investigação do processo de relação de crianças autistas com o objeto e com o outro em situação de brincadeira. Nessa atividade afirma-se que: 1) geralmente elas se comportam como se o outro não existisse e 2) a relação que estabelecem com o objeto é destituída de significado, tendendo a utilizá-lo em movimentos estereotipados ou como mero alvo de fixação. 
Assumindo uma postura de indagação diante dessas duas pressuposições, que sugerem um caráter imutável de aspectos do desenvolvimento infantil, este trabalho teve o objetivo de analisar os modos como crianças autistas se orientam para pessoas e objetos em situação de brincadeira em grupo, privilegiando indicadores da emergência de ações imaginativas, em especial aquelas vinculadas ao jogo de papéis ${ }^{2}$.

\section{Considerações metodológicas}

Para compor a base do estudo foram realizadas sessões de brincadeira, que eram coordenadas pela primeira autora (doravante referida como pesquisadora), com um grupo de três crianças autistas. Trata-se, portanto, de um contexto em que a pesquisadora coloca-se como elemento que faz parte da situação pesquisada, sem assumir uma posição de observador neutro. Sua ação no ambiente e os efeitos dessa ação são, assim, materiais relevantes para as análises.

A construção dos dados foi feita a partir de transcrições de vídeo e anotações de campo, e baseada na abordagem microgenética (Wertsch, 1985). Nessa opção metodológica, busca-se examinar minúcias e encontrar indícios das relações interpessoais e das ações em ocorrência. Góes (2000) destaca que a análise microgenética consiste em uma forma de registro e construção de dados que demanda a atenção a detalhes e a seleção de episódios que permitem examinar as relações intersubjetivas e as condições sociais da situação, de maneira a gerar um relato minucioso dos acontecimentos, especialmente dos diálogos.

Participaram desse estudo dois meninos e uma menina. A instituição em que são atendidos recebe casos de distúrbio global do desenvolvimento, incluindo quadros de autismo, e se localiza numa cidade de pequeno porte do interior paulista. Na seleção dos participantes, optamos por aqueles mais novos, o que configurou um grupo de três sujeitos com idade entre 6 e 12 anos. Foram feitos contatos com as mães para obtenção de sua anuência e assinatura do Termo de Consentimento Livre e Esclarecido. A seguir é apresentada uma breve caracterização dos três sujeitos, com base nos dados de prontuário e na entrevista com as mães, realizada pela pesquisadora.

- Luis: 6 anos de idade, com diagnóstico não estabelecido e classificação interrogada de Transtorno Invasivo do Desenvolvimento, Autismo Leve e Deficiência Mental. Sua fala é bastante comprometida; emite alguns sons, muitas vezes em relação a um determinado objeto. Em geral não responde a comandos verbais. Apresenta frequentes movimentos estereotipados com as mãos, grande agitação

2 O jogo de papéis, minuciosamente analisado por Elkonin (1984), tende a assumir formas complexas ao longo da infância, com incorporação de personagens, desdobramento das situações encenadas, concatenação de papéis entre participantes etc. Esclarecemos que essa denominação é aqui empregada para abranger também formas incipientes ou breves desse tipo de brincadeira. motora e dificuldade para permanecer na mesma atividade, mesmo por um tempo curto. Embora de forma não frequente, chega a olhar para o outro e a aceitar a aproximação ou o toque.

- Ana: 11 anos de idade, com diagnóstico de Autismo Atípico e Distúrbio Neuropsicomotor. Não fala, apenas emite alguns sons repetitivos, e não atende a comandos verbais. Apresenta ranger de dentes intenso e constante, agitação e dificuldade na coordenação motora. Fixa a atenção em objetos e resiste a se afastar deles, reagindo com autoagressividade. Interessa-se por objetos duros. Em raros momentos dirige o olhar ao outro, mas desvia quase que no mesmo instante.

- Paulo: 12 anos de idade, com diagnóstico de Autismo e Epilepsia. Não fala nem responde a comandos verbais; por vezes grita ou emite sons repetitivos. Apresenta frequentes movimentos estereotipados com as mãos e a cabeça. Não olha para o outro e age como se ninguém estivesse presente. Tende a manter o olhar fixo em alguma direção ou em algum objeto.

Ana e Paulo frequentam a instituição no período vespertino de segunda a sexta-feira, participando de atividades de vida diária e algumas consideradas pedagógicas, como recortes, colagem, pintura, encaixes etc. (a rotina da instituição não prevê horários de brincadeira e foi observado que, mesmo nos momentos de parque, essa atividade é solitária e ocasional). Uma vez por semana eles são atendidos por profissionais da equipe terapêutica, nas áreas de fonoaudiologia, psicologia, musicoterapia e fisioterapia. Em horários agendados, passam também com a pedagoga. Luís frequenta a instituição uma vez por semana, somente para o serviço de fonoaudiologia. Está incluído em classe de Educação Infantil de uma escola particular, no período matutino.

A fase preliminar do estudo de campo (contato com profissionais, crianças e mães) durou dois meses e a realização das sessões de brincadeira estendeu-se por sete meses; as atividades foram realizadas a intervalos irregulares, em geral quinzenais, devido à ocorrência de feriados, à falta dos alunos e à alteração de agenda pela instituição (transferência ou suspensão de atividades).

Nas sessões, a pesquisadora buscou envolver as crianças em brincadeiras, incentivando o contato interpessoal e construindo sentidos para as situações em ocorrência. Também criava condições para a emergência de ações imaginativas e, com esse propósito, apontava características e possibilidades de uso dos objetos. Para a atividade, foram escolhidos materiais que permitissem vários tipos de brincadeira (bolas coloridas, blocos de montar, massa de modelar, giz de cera etc.) e principalmente brinquedos que potencialmente favorecem jogos de faz de conta (boneca, utensílios de cozinha, kit de médico, kit de ferramentas, kit de beleza, carrinhos etc.).

Os encontros eram realizados por volta das $15 \mathrm{~h} 30$, após o lanche, horário em que as crianças eram liberadas e levadas ao parque, onde aguardavam para ir embora. As sessões tinham duração aproximada de trinta minutos e, sempre que possível, foram filmadas por auxiliares: um 
monitor dos alunos ou uma colaboradora, que era psicóloga e não pertencia à instituição. O material registrado corresponde ao total de treze sessões. Nas duas sessões iniciais, optamos por não ter a filmagem e privilegiamos facilitar a familiarização das crianças com a pesquisadora e a situação de grupo.

Quando não foi possível contar com um dos auxiliares de filmagem, os encontros tiveram um registro feito pela pesquisadora em diário de campo logo após seu término. Além de ser utilizado nessas circunstâncias, o diário também serviu para registro da observação dos sujeitos em outros momentos e espaços da instituição, como no horário do lanche, das atividades pedagógicas e da ida ao parque.

\section{Resultados e Discussão}

As análises do material registrado consistiram de exame detido do entrelaçamento do uso de brinquedos com as interações sociais durante as sessões, buscando indicadores da dinâmica de orientação para objetos e para pessoas que as crianças manifestavam. Interessava também relacionar essas manifestações à forma como a pesquisadora participava das situações de brincadeira. Por isso, os dados são apresentados sob dois temas: modos de brincar das crianças e modos de atuação do adulto.

\section{Modos de brincar das crianças}

Os registros indicam que os sujeitos mantêm a atenção nos brinquedos, mas também se dirigem à pesquisadora em muitos momentos das sessões e algumas vezes a outra criança, seja por um olhar rápido ou um sorriso, seja pelo envolvimento em alguma atividade. Para explorar este tema, organizamos as situações analisadas em três unidades: a) sorrindo e tocando; b) buscando provocar ações do outro; c) engajando em brincadeiras. Essas unidades não são mutuamente exclusivas, mas se distinguem em termos da ênfase que demos a determinadas ocorrências, relevantes para o objetivo. A seguir são apresentados episódios que ilustram a análise realizada (na referência à pesquisadora é usada a abreviação pesq.).

\section{a) Sorrindo e tocando}

Episódio 1: O sorriso de Paulo e a aproximação de Ana

A pesq. está sentada no chão com Ana, perto de brinquedos. Paulo está sentado na cadeira junto à mesa (como ocorreu com frequência em sessões anteriores). Ele segura uma panela de brinquedo e depois a solta no chão.

Pesq.: Como é que faz comida na panela, tem que mexer assim, não é?

A pesq. pega uma colher e mexe na panela. Ele permanece parado e manuseia a panela. Então afasta-se da pesq. encolhendo o corpo e virando o rosto para outra dire- ção, parecendo acanhado. Fica girando a panela no chão como se fosse um pião.

Pesq.: Você está com vergonha, Paulo?

Embora continue olhando em outra direção, ele sorri.

Ana está com uma boneca e começa a rodá-la de um lado para o outro. Então passa a mexer na cesta de utensílios de cozinha, parecendo procurar alguma coisa. Olha para a pesq. virando o corpo em sua direção e continua a mexer na cesta. Aparenta estar ansiosa, olhando fixamente para a pesq.

Pesq.: O que você está querendo, parece estar querendo me contar alguma coisa? O que você quer me contar?

Ana aproxima-se ainda mais da pesq., que, ao perceber esse comportamento, volta-se em sua direção, favorecendo a aproximação e mostrando-se contente com o gesto.

Pesq.: Quer ficar pertinho de mim?

Ana se aquieta e permanece ali sentada junto à pesq. remexendo os brinquedos.

Paulo começa a vocalizar alguns sons.

Pesq.: O Paulo está cantando?

Paulo desvia o olhar. Ana continua junto à pesq., mexendo nos brinquedos que estão próximos.

Nessa situação, o sorriso de Paulo indica uma receptividade aos dizeres da pesquisadora, o que até então era incomum. Geralmente ele não mostra comportamentos de correspondência às tentativas de contato; costuma desviar o olhar, permanecendo sério. Quanto a Ana, ao aproximar-se da pesquisadora, parece buscar um contato para fazer um pedido ou dizer algo, sugerido pelo olhar insistente e comportamento ansioso. A pesquisadora significa essa conduta com a pergunta: "O que você quer me contar?". Ana reage aproximando-se ainda mais e permanecendo junto a ela. O sentido atribuído às suas ações parece fazer um grande diferencial nessa relação e resultar na procura pelo outro. Entretanto, muitas vezes seus movimentos são simples e rápidos, como ocorre com Paulo, demandando uma observação constante para uma resposta do adulto que acolha e encoraje a continuidade de interação.

b) Buscando provocar ações do outro

Episódio 2: A disputa por brinquedos

Luis segura um secador de cabelos e mexe num balde com blocos de montar. Ana levanta-se tentando pegar o secador. Luis recusa-se a dar e provoca Ana, mostrando o brinquedo e se afastando. A pesquisadora procura acalmar os dois e tenta oferecer outros brinquedos para Ana. A menina insiste, irritada, e a disputa se intensifica.

Pesq.: Você está fugindo com o secador, hein, Luis!

Ele pega um carrinho e afasta-se. Coloca o carro sobre a mesa e afasta-se novamente, segurando o secador no alto.

Pesq.: Você está escondendo o secador?

Luis abaixa-se, pega um espelho e, sorrindo, faz movimentos afastando-o e aproximando-o dos olhos. 
Pesquisadora: Você está brava com o Luis, Ana, porque você quer o mesmo brinquedo que ele? E você aí está provocando ela, não é Luis?

$\mathrm{Na}$ continuação Luis oferece outros brinquedos à menina, que os pega e joga no chão. Luis então fica de frente para ela e começa a pular de um lado para o outro, rindo muito. A pesquisadora intervém para que aceitem outros objetos e conversa com os dois para atenuar o conflito. Luis passa a tomar outros brinquedos de Ana, mesmo os que ele que tinha oferecido (pente, escova, espelho). A certa altura, ainda com o secador, ele olha para Ana, ri muito e solta gritinhos. A pesq. encoraja Ana a brincar com o espelho. Em seguida a sessão é terminada.

Embora, à primeira vista, a situação não pareça ser de brincadeira e sim de conflito entre crianças que estão orientadas para um objeto, nossa interpretação é de que Luis brinca com Ana, num jogo semelhante ao "esconde-esconde". A pesquisadora tenta o tempo todo apaziguar o embate entre as duas crianças, e, pela fala, vai atribuindo sentido às suas ações, procurando significar a disputa em ocorrência. Apesar de envolver um desentendimento por vezes tenso, a situação mostra uma relação entre as duas crianças que não é de mera orientação para o objeto - de fato, Ana faz uma busca incessante pelo secador, mas o desdobramento sugere que a relação com o parceiro, e não o secador propriamente, é o que mobiliza a interação, em especial para Luis, que parece mais interessado em provocar a menina do que em ter a posse do secador, tanto assim que ele oferece e toma outros objetos (pente, escova, espelho) para manter o jogo de embate. Ou seja, a disputa (relação entre sujeitos) parece predominar sobre a orientação para os objetos.

c) Engajando em brincadeiras

Episódio 3: "Dando banho no bebê"

Sentada no chão junto à pesq., Ana pega uma boneca, segurando-a pela cabeça, tira o boné da boneca e começa a girá-la.

Pesq.: Vamos dar banho na boneca?

A menina lhe entrega a boneca.

Pesq.: Isso! Como a gente faz para dar banho na boneca? Tiramos a fraldinha da bonequinha...

Ana sorri, pega a boneca da mão da pesquisadora e fica olhando para o brinquedo. A pesq. pega a banheira, Ana continua segurando e olhando para a boneca.

Pesq.: Vamos dar banho na boneca? Vamos colocar o bebezinho aqui dentro da banheira para dar banho nela?

Sorrindo, Ana solta a boneca no chão.

Pesq.: Vamos cuidar do bebê? Como a gente faz? Vamos colocar ela aqui dentro, para dar banho no bebê? (a pesq. mostrando a banheira)

Ana segura a boneca, com semblante sério.

Pesq.: Quer colocar? Quer dar banho na bonequinha?

Ana segura a boneca pelo braço, levantando-a até a altura de seus olhos, olhando-a.
Pesq.: Você está vendo aí o bumbum do bebê. Vamos dar banho nela?

Ela olha para a banheira sorrindo, levanta a boneca com uma mão e com a outra mão cobre o rosto. Segura os pés da boneca, observando-os.

Pesq.: Esse é o pezinho do bebê.

Ela solta a boneca no chão, a pesq. aponta para seu

pé.

Pesq.: Olha o tamanho do seu pé e olha o tamanho de pezinho do bebê.

A atividade segue com Ana segurando, olhando e soltando a boneca e outros brinquedos, como o pente, o secador de cabelo e o espelho. Algum tempo depois, Ana volta a pegar a banheira e a brincadeira com o bebê é retomada. Ana sorri enquanto a pesq. conversa sobre a enxugar o bebê com a toalha e colocar a fralda.

Mesmo que não brinque com a boneca de forma autônoma, Ana mostra-se atenta e envolvida nas ações desse faz de conta. As falas da pesquisadora acompanham o manuseio dos brinquedos, compondo o significado de "dar banho no bebê" e incentivando a participação da menina, que se mantém atenta e faz movimentos de pegar e entregar a boneca ou a banheira. Esse jogo parece inclusive agradá-la, pois reage sorrindo em diversos momentos.

\section{Episódio 4: "Brincando de telefonar"}

Luis aproxima-se da pesq. e fica abraçado a ela por algum tempo, remexendo os brinquedos que estavam próximos. Ele pega uma cuba, um capacete e os coloca numa maleta. Vai até uma cesta com brinquedos e tira vários objetos de dentro dela. Pega uma chave de fenda e olha para o objeto fixamente.

Pesq.: É uma chave de fenda, é para gente consertar as coisas.

Luis guarda os objetos na maleta, pega um estetoscópio e o devolve na maleta. Em seguida pega a máscara de médico, cheira-a e guarda. Ele olha para a filmadora e afasta-se ficando de costas, parecendo esconder-se da câmera, enquanto realiza movimentos estereotipados de girar as mãos em frente do rosto. Depois anda pela sala, vai à mesa do computador, pega o mouse e o coloca no ouvido.

Pesq.: Esse aí é um telefone, como a gente atende ao telefone? Como a gente fala?

Ele põe o mouse sobre a mesa, mas pega novamente colocando-o no ouvido.

Luís: Ô. (balbuciando)

Pesq.: Você está falando alô?

Ele coloca novamente o mouse sobre a mesa, olha para o objeto, leva-o para o ouvido esquerdo, depois para o ouvido direito.

Luís: Ô, ô.

Pesq.: Você está dizendo alô?

Ele solta o objeto na mesa e com um dos dedos aperta o teclado do computador.

Pesq.: Você está discando os números, vai telefonar para alguém? 
Luis continua a apertar o teclado; depois sai sorrindo e pulando para o centro da sala.

Nesse episódio, ao atribuir às ações de Luis o sentido de telefonar, a pesquisadora favorece um movimento na criança, que age e balbucia sons correspondentes à brincadeira, até imitando a palavra "alô". A interação produz um momento de jogo imaginativo que, embora simples, já implica um desprendimento do campo perceptual imediato. Ou seja, por conta da relação entre sujeitos, o uso do objeto significado (telefone) impõe-se ao uso do objeto percebido, numa ação de caráter mais elaborado.

Considerando os três modos de brincar, os dados indicam que, em vários momentos, as crianças orientam-se para as pessoas presentes, buscando ou aceitando o contato com a pesquisadora e, ocasionalmente, com o parceiro. Quanto à orientação para objetos, elas os manipulam de diferentes formas (com movimentos repetitivos, por exemplo), mas por vezes conseguem usá-los como parte de ações imaginativas e o fazem, embora de maneira rudimentar, de acordo com o que observam sua vivência diária. Ainda que se envolvam mais com brinquedos que são reproduções em miniatura de coisas do cotidiano (fogão, secador, ferramenta etc.), chegam a atribuir novo significado a outros tipos de objetos (uso do mouse como "telefone").

Essas indicações de possibilidades são indissociáveis da participação da pesquisadora e remetem à tese da gênese social do desenvolvimento: nas relações com o outro, e a depender da qualidade dessas relações, a criança se desenvolve e vai se apropriando de experiências pertinentes a diferentes esferas de atividade na cultura. Essa ideia ampla de mediação social, como concebida pela teoria histórico-cultural, confere ao outro um papel constitutivo na formação do sujeito (Vigotski, 1999). Nesse sentido, o "dar banho no bebê", na brincadeira de Ana, não pode ter sua importância diminuída porque ela o faz com movimentos incipientes e somente sob o persistente incentivo do adulto. Essas são formas de imersão na vida social (Elkonin, 1984) essenciais para qualquer criança, especialmente a criança autista.

\section{Modos de atuação do adulto}

As ações dessas três crianças poderiam facilmente enquadrar-se nas descrições tradicionais do autismo no que concerne à forma como participam das brincadeiras e se relacionam com objetos e pessoas. Contudo, quando na atuação junto a elas, atentamos às minúcias e indícios de outros comportamentos e nos deslocamos da expectativa de uma preferência por objetos e de manipulação repetitiva ou comportamento bizarro no uso de brinquedos, vemos que elas extrapolam o esperado e mostram possibilidades diversas. Se, neste estudo, tivéssemos uma abordagem pautada somente nos comportamentos bastante característicos dos sujeitos, ficaria inviável pensar em qualquer possibilidade de desenvolver brincadeiras.
Nessa linha, cabe ressaltar a mediação da pesquisadora durante os encontros, nos quais permanecia bastante atenta aos movimentos dos sujeitos (uma condição indispensável para interagir com o autista, como salienta Bosa, 2002), desdobrando-se para atribuir sentidos a suas ações e ao uso de objetos, bem como às relações com os outros envolvidos na situação de brincadeira (como sugere Bagarollo, 2005). Devido à ausência da fala nas crianças, a pesquisadora falava com elas e por elas. Com isso, as relações sujeito-sujeito e sujeito-objeto se ampliaram em muitos momentos das sessões em resultado da atuação de um adulto que se orienta para a construção de sentidos e ensina a brincar. Aqui, o termo ensinar está relacionado à concepção ampla de uma mediação deliberada para envolver o sujeito num tipo de atividade. Não se trata meramente de recorrer ao objeto, que teria a preferência do autista, para então conseguir que ele estabeleça alguma comunicação, alguma ação conjunta, como tem sido sugerido em "orientações práticas" para lidar com esse sujeito. Mais que isso, importa envolvê-lo no processo de significação (que abrange inclusive momentos em que nenhum objeto está em questão) e colocá-lo numa rede de relações com outros.

Esse era um propósito previamente pensado pela pesquisadora. Por outro lado, as situações não eram propriamente "planejadas", pois não eram programadas nem tinham estruturação definida a priori. Por isso, é interessante examinar como se caracterizava a atuação do adulto na atividade com as crianças. Analisando o corpus da pesquisa, destacam-se três modos de atuação que parecem mais relevantes em termos do objetivo do trabalho.

1) O encorajamento do início ou da manutenção de contato com outros. Por meio da gestualidade e da fala, a pesquisadora incentivava a interação com a criança ao longo de todas as sessões, como pode ser visto nos episódios descritos. Também fazia esforços para que a criança se relacionasse com um parceiro presente, direcionando sua atenção para um colega ou interpretando para ela a ação de outro participante.

2) A construção de sentidos sobre brincadeiras e uso de brinquedos. Esse modo de atuação implicava dizeres a respeito da situação em ocorrência, sugerindo uma ação de faz de conta e muitas vezes abrangendo também características perceptuais e funcionais dos objetos envolvidos. Exemplos disso estão nos episódio 3 e 4, quando a pesquisadora encoraja Ana a dar banho no bebê (Vamos dar banho na boneca? Vamos colocar o bebezinho aqui dentro da banheira para dar banho nela?) e aponta para partes da boneca (o bumbum, o pezinho); ou quando tenta iniciar um jogo com Luis (É uma chave de fenda, é para gente consertar as coisas) e, depois, consegue envolvê-lo no brincar de telefonar.

3) A referência a estados subjetivos atribuídos à criança. Quanto a essa atuação, os dados indicam que, durante as sessões, a pesquisadora frequentemente tecia comentários sobre intenções, emoções e pensamentos que eram inferidos das ações da criança e os relacionava à situação em curso. Por exemplo, no episódio 1 , ela infere uma intenção de Ana ( $O$ que você está querendo, parece 
estar querendo me contar alguma coisa? O que você quer me contar?); também sugere a condição emocional de Paulo (Você está com vergonha, Paulo?). No episódio 2, reporta-se tanto à raiva de Ana como à intenção e à alegria de Luis (Você está brava com o Luis, Ana, porque você quer o mesmo brinquedo que ele? E você aí está provocando ela, não é Luis?).

Entendemos que esse tipo de diálogo pode gerar a atenção da criança sobre si ou o reconhecimento de seu mundo interior e não apenas a atenção a pessoas e coisas do meio social, implicadas nos outros modos de atuação apontados. Naturalmente a significação do "mundo exterior" pode também levar a uma atenção sobre si, mas aqui há uma canalização de sentidos específica nessa direção, que nos parece um importante componente do papel do outro no desenvolvimento de crianças autistas.

Retomando os modos de atuação da pesquisadora, os achados levam a reiterar a importância da mediação social e a ressaltar os efeitos da participação do outro sobre os processos da criança com desenvolvimento comprometido. Quando guiada pelas possibilidades e não pela incapacidade - nesse caso, de interagir e de agir imaginativamente -, essa participação propicia a elevação dos níveis de funcionamento da criança, como é argumentado por Vigotski (1997) nos textos de Defectologia. Nessa visão, não se nega a existência do comprometimento, mas se enfatiza a plasticidade do funcionamento humano, que permite a superação dos obstáculos decorrentes do déficit se o grupo social criar condições para iniciativas que tomem como ponto de partida quaisquer capacidades existentes na criança e propiciem novas capacidades, apostando assim no núcleo sadio do desenvolvimento.

Em termos de mediação da atividade dos sujeitos, constatamos que o encorajamento da pesquisadora esteve vinculado a todas as ocorrências de um brincar imaginativo quando o manuseio repetitivo ou dispersivo de brinquedos era transformado em uso contextualizado, envolvido em rudimentos do jogo de papéis. Os dados sobre modos de atuar da pesquisadora (o encorajamento de contato social, a construção de sentidos sobre brincadeiras e a referência a estados subjetivos da criança) mostram que, durante as brincadeiras, ela promoveu diferentes formas de orientação para pessoas. Suas iniciativas incentivavam a relação das crianças com os participantes presentes. Também ao se referir a estados subjetivos, ela efetuava um direcionamento da atenção da criança para si mesma.

Vale salientar, ainda, que a mudança na forma de manusear brinquedos e outros materiais na direção de um uso significativo e contextualizado não se ajusta à ideia de "orientação para o objeto" no sentido estrito das descrições dessa característica do autista. Isso porque a colocação do objeto numa cena de faz de conta já implica ocupar o lugar da pessoa que o usa e realizar uma ação atinente a certa esfera da cultura (por exemplo, brincar com a ferramenta para consertar o carro, ou com o fogão para fazer comidinha). Nesse caso está implicada uma forma distinta de envolvimento com outros, que não estão em presença, mas que representam membros do grupo social em atividade. Isso, do ponto de vista histórico-cultural, refere-se a um ganho fundamental dos processos envolvidos no brincar, por constituir um caminho essencial de apropriação da cultura.

\section{Considerações finais}

Com a mediação da pesquisadora durante a brincadeira, as crianças autistas chegaram a apresentar ações imaginativas, o que implica efetuar um desprendimento da situação imediato-concreta, pela qual a significação passa a subordinar a percepção (Vigotski, 1984). Essa subordinação é típica do brincar e se faz presente particularmente no jogo de papéis, em que há recriação de situações do cotidiano, envolvendo ações sobre objetos e relações entre pessoas (Elkonin, 1984). Trata-se de um processo de retomada da realidade vivida que usualmente se transforma na linha de uma crescente criatividade.

Como indicado, as sessões foram realizadas sem uma programação de materiais e instruções específicas, diferentemente do que ocorre sob a diretriz de algumas vertentes de trabalho com autistas. Por outro lado, a participação da pesquisadora teve o claro intuito de encorajar a relação interpessoal e explorar indícios de possibilidades do uso significativo de objetos. Com base numa visão ampla dos "outros" envolvidos na situação de brincadeira, as análises indicam que o incentivo à orientação para pessoas abrangeu os outros presentes (pesquisadora e parceiros) e a própria criança (nas referências feitas a seu estado subjetivo), bem como as personagens envolvidas na ação imaginativa (representativas de figuras do grupo social).

Com isso, em vários momentos, os sujeitos chegaram a se envolver no jogo de papéis. Embora essas ações imaginativas tivessem um caráter incipiente e pouco frequente ao longo das sessões, o seu valor não deve ser subestimado, visto que o mais importante está no fato de os sujeitos se mostrarem responsivos ao encorajamento do adulto na direção de refinar capacidades que constituem avanços numa área essencial ao desenvolvimento na infância.

Os achados sugerem que, se nos afastarmos da crença na dicotomia de preferência por "objetos versus pessoas", afirmada na maioria dos estudos da área, e da pressuposição de que o outro é evitado ou apenas "usado" pelo autista, talvez possamos enxergar diferentes nuances de qualidade em suas manifestações.

Em suma, este estudo permite questionar não somente como o autista se relaciona com o outro, mas como o outro se relaciona com o autista e, desse modo, questionar as práticas sociais voltadas ao cuidado e atendimento a esse sujeito. Essa perspectiva de interpretação remete à necessidade de superar a atuação guiada pelo transtorno, isto é, principalmente pelas impossibilidades e pela busca de eliminação de sintomas indesejáveis, e a instauração de uma atuação dirigida à identificação de condições de funcionamento intersubjetivo que propiciem a significação das vivências do autista e, de modo geral, sua inserção na cultura. 


\section{Referências}

American Psychiatric Association. (1995). Manual Diagnóstico e Estatístico de Transtornos Mentais (DSM - IV). Porto Alegre: Artes Médicas.

Bagarollo, M. F. (2005). A Ressignificação do Brincar das Crianças Autistas. Dissertação de Mestrado, Universidade Metodista de Piracicaba - UNIMEP, Piracicaba, São Paulo.

Bosa, C. (2002). Autismo: Atuais Interpretações para Antigas Observações. Em C. R. Baptista \& C. Bosa (Orgs.), Autismo e Educação: Reflexões e Propostas de Intervenção (pp. 21-39). Porto Alegre: Artmed.

Bragin, J. M. B. (2011). Práticas Pedagógicas com alunos autistas na Escola Especial. Dissertação de Mestrado, Universidade Metodista de Piracicaba-UNIMEP, Piracicaba, São Paulo.

Cruz, T. S. U. R. (2009). Acompanhamento da experiência escolar de adolescentes autistas no ensino regular. Dissertação de Mestrado em Educação, Universidade Metodista de Piracicaba-UNIMEP, Piracicaba, São Paulo.

Elkonin, D. B. (1984). Psicología del juego. Havana: Pueblo y Educación.

Góes, M. C. R. (2000). A Abordagem Microgenética na Matriz Histórico-Cultural: Uma Perspectiva para o Estudo da Constituição da Subjetividade. Cadernos Cedes 20 (50), 9-25.

Leontiev, A. N. (1986). Os princípios psicológicos da brincadeira préescolar. Em L. S. Vygotski, A. R. Luria \& A. N. Leontiev, Linguagem, desenvolvimento e aprendizagem (pp.119-142). São Paulo: Ícone/ Edusp.

Marcelli, D. (1998). Manual de Psicopatologia da Infância e da Adolescência de Ajuriaguerra. Porto Alegre: Artes Médicas.

Martins, A. D. F. (2009). Crianças autistas em situação de brincadeira: apontamentos para as práticas educativas. Dissertação de Mestrado, Universidade Metodista de Piracicaba-UNIMEP, Piracicaba, São Paulo.
Mattos, L. K., \& Nuemberg, A. H. (2011). Reflexões sobre a inclusão escolar de uma criança com diagnóstico de autismo na educação infantil. Revista Educação Especial, 24(39), 129-142.

Organização Mundial da Saúde. (1993). Classificação de Transtornos Mentais e do Comportamento da CID - 10: Descrições Clínicas e Diretrizes Diagnósticas. Porto Alegre: Artes Médicas.

Orrú, S. E. (2008). Os estudos da análise do comportamento e a abordagem histórico-cultural no trabalho educacional com autistas. Revista Iberoamericana de Educação, 45(3), 1-12.

Orrú, S. E. (2010). Contribuições da abordagem histórico-cultural na educação de alunos autistas. Humanidades Médicas, 10(3), 1-18.

Rocha, M. S. P. M. L. (2005). Não Brinco mais: a (Des)Construção do Brincar no Cotidiano Educacional. Ijuí, RS: Editora Unijuí.

Soifer, R. (1992). Psiquiatria Infantil Operativa. Porto Alegre: Artes Médicas.

Schwartzman, J. S., \& Araújo, C. A. (Orgs.). (2011). Transtornos do espectro do autismo. São Paulo: Memnon.

Vasques, C. K. (2008). Transtornos globais do desenvolvimento e educação: análise da produção Científico-Acadêmica. Trabalho apresentado na $33^{\circ}$ Reunião da ANPED. Recuperado: $15 \mathrm{dez}$ 2008. Disponível: htpp://www.anped.org.br/33encontro/

Vigotski, L. S. (1984). A Formação Social da Mente. São Paulo: Martins Fontes.

Vigotski, L. S. (1987). La Imaginación y el Arte en la Infância. Cidade do México: Hispânicas.

Vigotski, L. S.(1997). Fundamentos de Defectologia. Obras Escogidas, Tomo V. Madri: Visor.

Vigotski, L. S. (1999). O Desenvolvimento Psicológico na Infância. São Paulo: Martins Fontes.

Wertsch, J. V. (1985). Vygotsky and the social formation of mind. Cambridge, Mass.: Harvard University Press. 
Recebido em: 03/11/11

Reformulado em: 29/10/12

Aprovado em: 31/01/13

Sobre as autoras

Alessandra Dilair Formagio Martins (alessandra.formagio@bol.com.br)

Doutoranda do Programa de Pós-graduação em Educação da Universidade Metodista de Piracicaba.

Endereço: Rua Romário Capossoli, n 19, Jardim Itamaracá, Indaiatuba-SP, CEP. 13335-600.

Maria Cecília Rafael de Góes (ceciliargoes@hotmail.com)

Livre Docente pela Universidade Estadual de Campinas, Orientadora-colaboradora do Programa de Pós-graduação em Educação da Universidade Metodista de Piracicaba.

Endereço: Rua Fernando Febeliano da Costa, no. 1419 apto. 102, Piracicaba-SP, CEP 13416-253.

Apoio PROESP/ CAPES 